\title{
Low temperature curing coating technology for corrosion under insulation mitigation
}

\author{
Mike O’Donoghue, Vijay Datta, Ian Fletcher, and George Sykes*
}

AkzoNobel, Stoneygate Lane, Gateshead NE100EX, U.K.

\begin{abstract}
In the oil and gas industry, the application of epoxy phenolic coatings has been the main route to obtain high heat resistance from coatings and to mitigate corrosion under insulation (CUI) of both insulated carbon and stainless steel pipes operating up to $200^{\circ} \mathrm{C}$. These coatings, however, are sensitive to overapplication, are prone to cracking and costly to repair when damaged. Additionally, if they are applied below $10^{\circ} \mathrm{C}$ epoxy phenolic coatings do not cure properly and can fail prematurely, and when applied close to this temperature, can impact shop heating costs, maintenance schedules, and productivity.
\end{abstract}

\section{Traditional Coating Solutions}

In order to produce epoxy coatings, epoxy resins are used to cross-link a variety of curing agents (e.g., amines, polyesters, mercaptans, fatty acids, and acrylics). The ensuing cross-link density is envisaged as the distance between the cross-links per unit of length. A high cross-link density will yield high chemical resistance and lower flexibility. Lower cross-link density linings, conversely, yield lower chemical resistance and greater flexibility.

All things being equal, the greater the functionality of the epoxy resin (n) the greater will be the cross-link density of the epoxy coating and the greater the temperature resistance of the coating, say for a given CUI mitigation service.

Bisphenol A resins have the lowest functionality $(\mathrm{n}=$ 1.9) of the three classes and are mainly used to produce solvent based and solvent free epoxy coatings for less severe environments. They can be co-reacted with high functionality curing agents to produce immersion grade coatings suitable for CUI services at temperatures up to ca $300^{\circ} \mathrm{F}\left(149^{\circ} \mathrm{C}\right)$.

Bisphenol $\mathrm{F}$ resins have a higher functionality $(\mathrm{n}=$ 2.1) and are smaller and less viscous, and possess a higher molecular mobility than the Bisphenol A resins. There is a lower steric hindrance of the methylene bridges in Bisphenol $\mathrm{F}$ resins compared to the higher steric hindrance from isopropylidene bridges in Bisphenol A resins.

Bisphenol $\mathrm{F}$ resins can be co-reacted with high functionality curing agents to produce greater, (a) crosslink density, (b) chemical resistance and (c) temperature resistance of the immersion grade epoxy.

Not surprisingly, epoxy phenolic coatings are the time proven workhorse for high heat and CUI mitigation in the temperature range of $4^{\circ} \mathrm{C}$ to $175^{\circ} \mathrm{C}$ for carbon steel and $50^{\circ} \mathrm{C}$ to $175^{\circ} \mathrm{C}$ for stainless steel. The upper temperature threshold that an epoxy phenolic coating would normally handle for non-insulated structures would be around $200^{\circ} \mathrm{C}$.

Novolacs are multifunctional and viscous resins $(\mathrm{n}=$ 2.5 to 3.4) and offer the potential to maximize the chemical and thermal resistance of an epoxy coating when cross-linked with judiciously selected curing agents. The cross-link density, glass transition temperature $(\mathrm{Tg})$, and thermal and chemical resistance of epoxy coatings may follow the rough order of epoxy novolacs $>$ Bisphenol F-based (phenolic) epoxies $>$ Bisphenol A-based epoxies. However, this is very much an oversimplification.

Although epoxy novolacs have high water, chemical and temperature resistance, on the downside their high cross-link densities give rise to epoxy films with increased brittleness and reduced toughness.

While cross-linked densities of epoxy coatings are related to the functionality and molecular length of their epoxy resins, it should be emphasized that the curing agent structure and reactivity also plays a pivotal role in the thermal and chemical resistant properties of the film.

\section{Alkylated Amine Epoxy Technology}

The differences in the chemistry and network of an epoxy phenolic coating and the step change alkylated amine epoxy can be pictorialized in the schematic diagram shown in Fig. 1.

\footnotetext{
* Corresponding author: danna.emelyanenko@akzonobel.com
} 
Traditional Epoxy

Phenolic

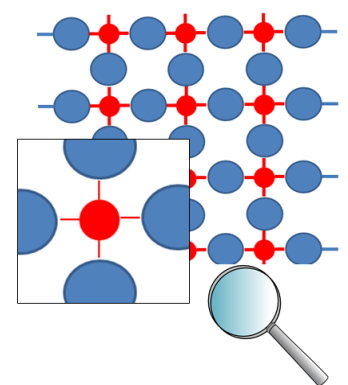

Rigid network

(restricts film DFT tolerance)
Alkylated Amine Epoxy

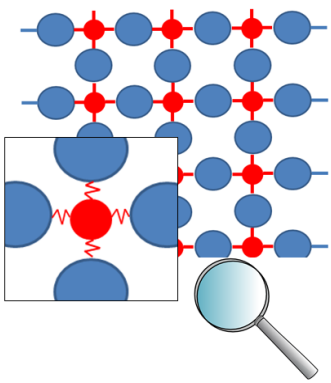

Flexible network (increases film DFT tolerance)
Fig. 1. Traditional Epoxy Phenolic and Alkylated Amine Networks.

Protecting process pipes from the ravages of high heat and CUI, epoxy phenolic coatings have an excellent track record and have performed admirably for asset owners worldwide.

From a practical standpoint the minimum curing temperatures of around $10^{\circ} \mathrm{C}$ and long cure times coupled with a sensitivity to overbuild the epoxy phenolic coating negatively impacts fabricators who experience delays in both moving and shipping coated steel pipe from the shop and field crew erecting the pipe at the job site.

Time-temperature drying data for a traditional epoxy phenolic coating is presented in Table 1.

Table 1. Traditional Epoxy Phenolic for High Heat and CUI service.

\begin{tabular}{|c|c|c|c|}
\hline Temperature & $\begin{array}{c}\text { Touch Dry } \\
\text { (hrs) }\end{array}$ & $\begin{array}{c}\text { Hard Dry } \\
\text { (hrs) }\end{array}$ & $\begin{array}{c}\text { Min } \\
\text { Overcoating } \\
\text { (hrs) }\end{array}$ \\
\hline$-5^{\circ} \mathrm{C}$ & NA & NA & NA \\
\hline $10^{\circ} \mathrm{C}$ & 8 & 16 & 36 \\
\hline $15^{\circ} \mathrm{C}$ & 7 & 12 & 24 \\
\hline $25^{\circ} \mathrm{C}$ & 6 & 8 & 16 \\
\hline $40^{\circ} \mathrm{C}$ & 3 & 6 & 16 \\
\hline
\end{tabular}

In contrast, productivity and logistics issues associated with the use of traditional epoxy phenolics have been overcome with the alkylated amine epoxy. The latter forms a robust film and can be applied at low substrate temperatures, cures at low temperatures, and cures rapidly with minimal touch dry and hard dry times as shown in Table 2 .

Table 2. Alkylated Amine Epoxy for High Heat and CUI service.

\begin{tabular}{|c|c|c|c|}
\hline Temperature & $\begin{array}{c}\text { Touch Dry } \\
\text { (hrs) }\end{array}$ & $\begin{array}{c}\text { Hard } \\
\text { Dry } \\
\text { (hrs) }\end{array}$ & $\begin{array}{c}\text { Min } \\
\text { Overcoating } \\
\text { (hrs) }\end{array}$ \\
\hline$-5^{\circ} \mathrm{C}$ & 7 & 10 & 14 \\
\hline $10^{\circ} \mathrm{C}$ & 5 & 8 & 10 \\
\hline $20^{\circ} \mathrm{C}$ & 4 & 6 & 7 \\
\hline $35^{\circ} \mathrm{C}$ & 2 & 4 & 4 \\
\hline
\end{tabular}

For the coating applicator, the high DFT tolerance of the alkylated amine epoxy reduces the risk of an overly thick film cracking. This is unlike the case for conventional epoxy phenolic coatings which have a propensity to crack at far lower threshold DFT values.

Tables 3 and 4 illustrate the tolerances to overapplication for an alkylated amine epoxy coating (as a function of temperature) compared to a traditional epoxy phenolic coating.

Table 3. Tolerance to DFT Over-application For a Traditional Epoxy Phenolic.

\begin{tabular}{|c|c|c|c|}
\hline $\begin{array}{c}\text { Conventional } \\
\text { Epoxy } \\
\text { Phenolic }\end{array}$ & $120^{\circ} \mathrm{C}$ & $150^{\circ} \mathrm{C}$ & $200^{\circ} \mathrm{C}$ \\
\hline \multirow{7}{*}{$\begin{array}{l}2 \times 225 \mu \mathrm{m} \text { DFT } \\
\text { stoved at } 200^{\circ} \mathrm{C}\end{array}$} & $1 \times 200 \mu \mathrm{m}$ & $1 \times 200 \mu \mathrm{m}$ & $1 \times 200 \mu \mathrm{m}$ \\
\hline & $2 \times 100 \mu \mathrm{m}$ & $2 \times 100 \mu \mathrm{m}$ & $2 \times 100 \mu \mathrm{m}$ \\
\hline & $2 \times 150 \mu \mathrm{m}$ & $2 \times 150 \mu \mathrm{m}$ & $2 \times 150 \mu \mathrm{m}$ \\
\hline & $2 \times 175 \mu \mathrm{m}$ & $2 \times 175 \mu \mathrm{m}$ & $2 \times 175 \mu \mathrm{m}$ \\
\hline & $2 \times 200 \mu \mathrm{m}$ & $2 \times 200 \mu \mathrm{m}$ & $2 \times 200 \mu \mathrm{m}$ \\
\hline & $2 \times 225 \mu \mathrm{m}$ & $2 \times 225 \mu \mathrm{m}$ & $2 \times 225 \mu \mathrm{m}$ \\
\hline & $2 \times 250 \mu \mathrm{m}$ & $2 \times 250 \mu \mathrm{m}$ & $2 \times 250 \mu \mathrm{m}$ \\
\hline
\end{tabular}

Light grey - good, no visible defects;

Medium grey - cracking and defects observed around weld only;

Dark grey - cracking and defects observed around face of panel.

Table 4. Tolerance to DFT Over-application of DFT For an Alkylated Amine Epoxy.

\begin{tabular}{|c|c|c|c|}
\hline $\begin{array}{c}\text { Alkylated } \\
\text { Amine Epoxy }\end{array}$ & $\mathbf{1 2 0}^{\circ} \mathbf{C}$ & $\mathbf{1 5 0}^{\circ} \mathbf{C}$ & $\mathbf{2 0 0}^{\circ} \mathbf{C}$ \\
\hline \multirow{4}{*}{} & $1 \times 200 \mu \mathrm{m}$ & $1 \times 200 \mu \mathrm{m}$ & $1 \times 200 \mu \mathrm{m}$ \\
\cline { 2 - 4 } & $2 \times 100 \mu \mathrm{m}$ & $2 \times 100 \mu \mathrm{m}$ & $2 \times 100 \mu \mathrm{m}$ \\
\cline { 2 - 4 } & $2 \times 125 \mu \mathrm{m}$ & $2 \times 125 \mu \mathrm{m}$ & $2 \times 125 \mu \mathrm{m}$ \\
\cline { 2 - 4 } $2 \times 250 \mu \mathrm{m} D F T$ \\
& $2 \times 150 \mu \mathrm{m}$ & $2 \times 150 \mu \mathrm{m}$ & $2 \times 150 \mu \mathrm{m}$ \\
\cline { 2 - 4 } & $2 \times 175 \mu \mathrm{m}$ & $2 \times 175 \mu \mathrm{m}$ & $2 \times 175 \mu \mathrm{m}$ \\
\cline { 2 - 4 } & $2 \times 200 \mu \mathrm{m}$ & $2 \times 200 \mu \mathrm{m}$ & $2 \times 200 \mu \mathrm{m}$ \\
\cline { 2 - 4 } & $2 \times 250 \mu \mathrm{m}$ & $2 \times 250 \mu \mathrm{m}$ & $2 \times 250 \mu \mathrm{m}$ \\
\hline
\end{tabular}

Aside from the enhanced productivity, and ease of use for fabricators and coating contractors, the alkylated amine epoxy was designed with simplicity in mind for engineers and specification authorities in order to reduce the number of coatings on specifications without sacrificing performance.

For process pipes, the alkylated amine epoxy maximum temperature resistance is $230^{\circ} \mathrm{C}$ and it is used for both insulated and uninsulated carbon and stainless steel operating between $-196^{\circ} \mathrm{C}$ and $205^{\circ} \mathrm{C}$. From testing according to the ISO12944-9 protocol, this epoxy 
exhibits excellent corrosion protection (see Fig. 3) and has shown corrosion creep values below $3 \mathrm{~mm}$ away from the scribe.

Interestingly, for non-insulated process pipes, the alkylated amine epoxy eliminates the temperature and humidity requirements associated with the application of inorganic zinc coatings. This translates to superior coating quality and productivity in all climate conditions.

The Houston Pipe accelerated laboratory test was used to evaluate the performance of the alkylated amine epoxy for use as a specialty coating for CUI mitigation. A two-coat application of this coating performed well and better than a two-coat application of a conventional epoxy phenolic as shown in Fig. 2.

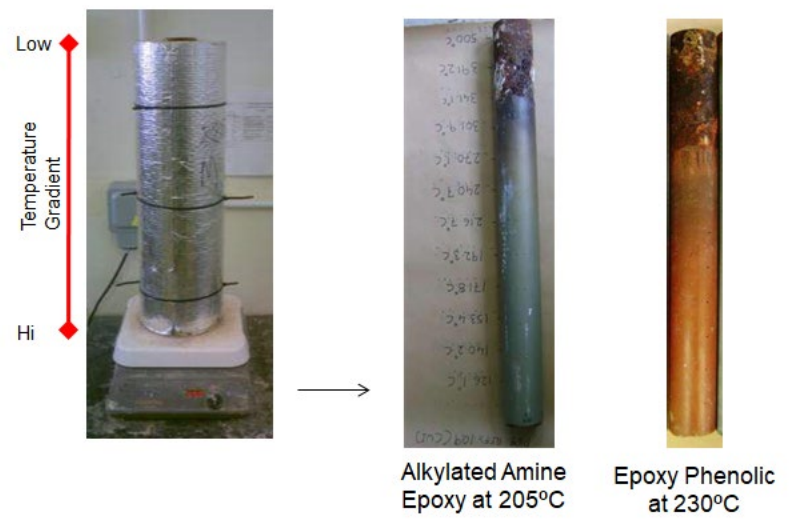

Fig. 2. CUI Resistance from Houston Pipe Test.

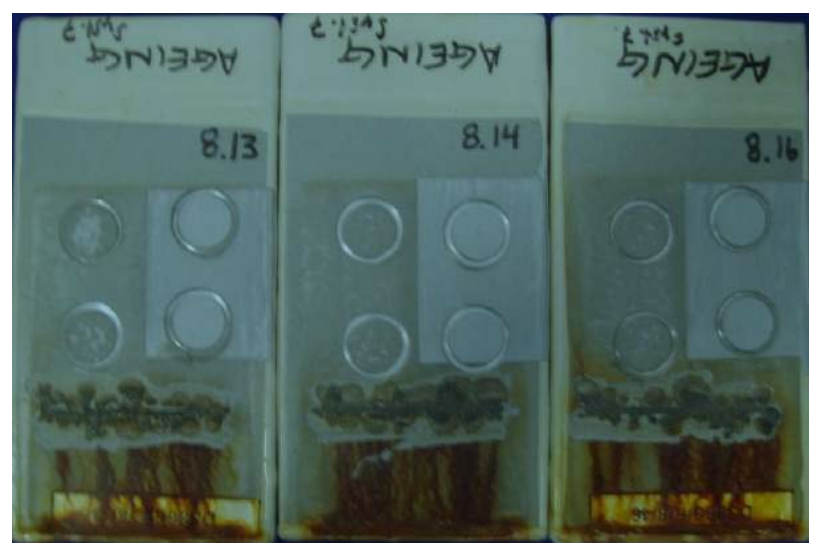

Fig. 3. ISO12944-9 testing of Alkylated Amine Epoxy.

\section{Case Study}

To support plans for increased power generation in South-East Asia, a new build geothermal power plant needed to be commissioned. Deadlines were tight and costs needed to be minimized in order to complete the project within budget. To meet these ambitious targets, a novel approach to coating selection was required.

The major challenge was the massive complexity of the project which, if not addressed, would contribute to a large rework spend and reduced productivity. Large volumes of bulk supplied items such as pipes, valves and vessels were needed, operating at different temperatures and service environments with and without insulation. Traditional coating systems are designed to offer corrosion protection over a limited range of service environments and temperatures and previous projects needed more than seven different coatings to protect the various pipes, valves and vessels.

On previous projects, the challenge of coating specification complexity had caused:

-Reduced productivity at the application stage;

-Increased chance of errors requiring rework, adding application cost;

-Increased rework costs onsite during the construction phase as equipment arriving with the incorrect coating system for the final operating environment was reworked to a correct coating;

-Increased risk of CUI and other corrosion issues on the finished plant, increasing $M \& R$ costs.

Training was difficult with a painting workforce that rapidly changed depending on workload, and so the challenge was on to cut costs and guarantee delivery of the project on time.

Traditional anti-corrosive solutions had been shown to add cost and complexity so the project team decided to look for a proven and reliable alternative solution.

The decision was taken to apply the UPC approach to the project, using one 'Universal Pipe Coating' to paint all pipes, valves and vessels. Standardizing the approach to coating specification greatly simplified the painting process, increasing productivity and improving quality. See Table 5.

Based on alkylated amine epoxy technology, Interbond 2340UPC is a temperature resistant coating from AkzoNobel providing excellent corrosion protection from $-196^{\circ} \mathrm{C}$ to $230^{\circ} \mathrm{C}$. Designed to maximize productivity versus traditional epoxy phenolic and inorganic zinc silicate type systems, Interbond 2340UPC also offers various application benefits:

-Excellent DFT tolerance to over-application reduces rework costs;

-Short overcoating intervals maximize productivity during the application process;

-Low temperature cure, down to $-5^{\circ} \mathrm{C}$, reduces heating costs in the winter months;

-Greater resistance to chalking than traditional epoxy phenolics, improving lifetime.

In addition, several additional benefits were reported, helping to cut costs and reduce the risk of early failure:

-Reduced number of coats allows applicators to increase productivity and reduce mistakes;

-Easier stock management, reducing waste;

-Easier application versus traditional epoxy phenolics and inorganic zinc silicate coatings, further reducing rework costs.

Feedback from the client stated that applying the 'UPC Approach' with Interbond 2340UPC to all pipes, valves and vessels saved approximately $10 \%$ on overall rework costs over the course of the project, as well as greatly improving productivity and helping to ensure the maximum performance in operation. 
Table 5. Reduced specification complexity with a Universal Pipe Coating system.

\begin{tabular}{|c|c|c|c|c|}
\hline $\begin{array}{c}\text { System } \\
\text { Number }\end{array}$ & $\begin{array}{c}\text { Temper } \\
\text { ature } \\
\text { Range }\end{array}$ & $\begin{array}{c}\text { Surface } \\
\text { Preparation }\end{array}$ & $\begin{array}{c}\text { Traditiona } \\
\text { I system }\end{array}$ & $\begin{array}{c}\text { Universal } \\
\text { Pipe } \\
\text { Coating } \\
\text { System }\end{array}$ \\
\hline $\begin{array}{c}\text { Uninsulate } \\
\text { d Carbon } \\
\text { Steel-1 }\end{array}$ & $\begin{array}{l}-45 \text { to } \\
60^{\circ} \mathrm{C}\end{array}$ & $\begin{array}{c}\text { NACE No. } 2 / \\
\text { SSPC-SP10 / } \\
\text { Sa2.5 }\end{array}$ & \begin{tabular}{|l|} 
Inorganic \\
Zinc \\
Silicate \\
Epoxy \\
Polyuretha \\
ne
\end{tabular} & \multirow{5}{*}{$\begin{array}{c}\text { Alkylated } \\
\text { Amine } \\
\text { Epoxy }\end{array}$} \\
\hline $\begin{array}{c}\text { Uninsulate } \\
\text { d Carbon } \\
\text { Steel-2 }\end{array}$ & $\begin{array}{l}-45 \text { to } \\
120^{\circ} \mathrm{C}\end{array}$ & $\begin{array}{l}\text { NACE No. } 2 / \\
\text { SSPC-SP10 / } \\
\text { Sa2.5 }\end{array}$ & \begin{tabular}{|l|} 
Zinc Epoxy \\
Epoxy \\
Polyuretha \\
ne
\end{tabular} & \\
\hline $\begin{array}{c}\text { Insulated } \\
\text { Carbon } \\
\text { Steel-1 }\end{array}$ & $\begin{array}{l}-45 \text { to } \\
60^{\circ} \mathrm{C}\end{array}$ & $\begin{array}{l}\text { NACE No.2 / } \\
\text { SSPC-SP10 / } \\
\text { Sa2.5 }\end{array}$ & $\begin{array}{l}\text { High build } \\
\text { Epoxy }\end{array}$ & \\
\hline $\begin{array}{c}\text { Insulated } \\
\text { Carbon } \\
\text { Steel-2 }\end{array}$ & $\begin{array}{l}-45 \text { to } \\
150^{\circ} \mathrm{C}\end{array}$ & $\begin{array}{c}\text { NACE No.2 / } \\
\text { SSPC-SP10 / } \\
\text { Sa2.5 }\end{array}$ & $\begin{array}{l}\text { Epoxy } \\
\text { Phenolic }\end{array}$ & \\
\hline $\begin{array}{l}\text { Insulated } \\
\text { Carbon } \\
\text { Steel-3 }\end{array}$ & $\begin{array}{l}-45 \text { to } \\
205^{\circ} \mathrm{C}\end{array}$ & $\begin{array}{c}\text { NACE No.2 / } \\
\text { SSPC-SP10 / } \\
\text { Sa2.5 }\end{array}$ & \begin{tabular}{|l|} 
Epoxy \\
Novolac or \\
Silicone \\
Hybrid
\end{tabular} & \\
\hline
\end{tabular}

\section{Conclusion}

A step change alkylated amine epoxy coating has been identified that possess high heat resistance for insulated and non-insulated steel structures.

The alkylated amine epoxy is atypical of conventional epoxy phenolic coatings. It has a low temperature and rapid cure characteristics, is tolerant of DFT overapplication, is easy to use for applicators and affords productivity enhancements for fabrication shops.

All text and images are property of AkzoNobel.

Elements of this article previously published in JPCL March 2018. 